Santarcangelo, Vincenzo; Terrone, Enrico (2015)

"Sounds and Other Denizens of Time",

The Monist, 98, 2, pp. 168-180. 


\title{
Sounds and Other Denizens of Time
}

\author{
Vincenzo Santarcangelo and Enrico Terrone
}

\section{Purely temporal individuals}

On the scientific worldview, space and time are taken to be the inextricable dimensions of a single structure called space-time. Everything that exists in time also exists in space. There are no instants or intervals in time detached from spatial locations.

Space and time are closely intertwined even in the ordinary worldview. We ascribe reality primarily to things such as portions of matter, living organisms and concrete artifacts - that is, individual things that exist in space-time. However, the ordinary worldview seems to have room also for individual entities existing in time but not in space. Minds or souls were once prominent candidate entities of this sort, but nowadays the most favored examples are entities created within certain social and cultural practices.

In this respect, Rohrbaugh $(2003,200)$ talks about "historical individuals" such as linguistic texts or musical compositions being "in time but not in space." Thomasson $(1999,36)$ describes fictional characters as "abstract artifacts" that "lack a spatiotemporal location," but specifies that their existence can have a beginning and an end in time. Ferraris $(2005,42)$ claims that social objects such as debts, contracts, and even nations "do not exist as such in space but subsist as traces (inscriptions, records in people's minds) and, through these traces, acquire duration in time". Smith (2003, 23) calls "freestanding Y terms" objects like symphonies, debts or corporations, which can exist independently of a particular spatial embodiment, and observes that "a symphony (as contrasted with the performance of a symphony) is not a token physical entity at all; rather - like a debt, or a corporation - it is a special type of abstract formation (an abstract formation with a beginning, and perhaps an ending, in time)." Scruton (2009, 50) argues that sounds also are purely temporal entities since they basically are "pure events [...] identifiable separately both from the things that emit them and from the places where they are located."

In this paper we propose to clarify 1) in what sense there may be individual entities that exist only in time and 2) what relationship links the existence of such purely temporal entities with the 
existence of spatiotemporal entities. We believe that this will help shed light on the relation between the scientific worldview - according to which what is real must have a spatiotemporal location - and the ordinary worldview, for which reality does not seem to boil down to what can be located in space-time.

Clearly, the notion of existence in space-time is tightly connected to that of objective reality. It is so tightly connected that every ontological commitment to the reality of some non-spatial individual entity seems to require an explanation of how that entity relates to existence in spacetime. Therefore, the possibility of a purely temporal existence is a decisive test to determine what room to maneuver a more adequatist realist philosophy may have compared to an austere version of realism that is committed only to the existence of what is spatiotemporal.

\section{The No-Space world}

A purely temporal individual entity is such that we can establish when but not where it is. One can think of these individuals (for example a sound) as having only temporal parts and temporal features in spite of their being dependent on more basic entities that have also spatial features (such as a body emitting the sound). But could such individuals exist entirely independently of any commitment to space? Strawson explores a positive answer to this question in chapter II of his Individuals, by means of a thought experiment concerning what he calls a No-Space world. In the first instance, this experiment aims at putting pressure on the Kantian thesis that space is a necessary condition for any "objective" experience, by which he means any experience of individual entities as existing independently of their being experienced.2 Strawson, in contrast, adopts the Aristotelian view according to which our most basic schemes and categories provide us with crucial clues as to the basic structures of reality, and thus he conceives space and time as structures of reality and not just as forms of experience. Given our experience of the world, the world must be such that it makes this kind of experience possible. So, Strawson is here discussing the thesis that space is a necessary condition not only for any objective experience, but also for any objective reality.

The No-Space world, as Strawson conceives it, is a purely auditory world. It has a temporal but no spatial dimension. He thus treats sounds as paradigmatic case of entities that may appear

2 In The Bounds of Sense (§ 2.III.3), Strawson explicitly reads Kant’s refutation of idealism as an “objectivity argument" arguing that "Kant has shown the necessity of something abiding and permanent, viz. the whole frame of Nature." 
to be purely temporal.3 His question is: can there be purely temporal entities or is it rather the case that, even when an entity seems to be purely temporal, there must still be some underlying spatial dimension that needs to be made explicit?

It is worth noting that sounds are here just the means to the end of investigating an ontological claim about space and time. Strawson is not making an empirical claim in the philosophy of perception about the nature of hearing in human beings. Nor is he making an ontological claim addressing questions like: are sounds individuals? are they events? are they properties of sounding objects? Rather, he is building up a thought experiment aimed at testing the metaphysical claim according to which the notion of space is necessary for any conception of an objective reality. Thought experiments, from Strawson's perspective, are just "models against which to test and strengthen our own reflective understanding of our own conceptual structure" $(1959,86)$. More specifically, the No-Space world is a device for putting pressure upon our notion of an objective reality.

This clarification is required because, in recent philosophy, Strawson's thought experiment on the No-Space world has been primarily discussed in the field of philosophy of perception as an account of auditory experience and the nature of sounds; thus it has been largely overlooked in ontological and metaphysical debates about realism.4 Here we aim to put this experiment back in its rightful place. Philosophy of perception is relevant only in regard to the assumptions of Strawson's experiment, inasmuch as to conceive of a purely auditory world requires that we conceive of a purely auditory experience. If such an experience is not conceivable, then the experiment fails.

In what follows we will argue that Strawson's assumptions are correct and that the No-Space world reflects a coherent thought experiment. We will then attempt to extend the results of his experiment to other families of examples with the goal of providing support for a realist ontology especially as concerns certain objects of social and cultural sciences.

\footnotetext{
3 In a similar vein, Nicod (1924) wonders what conception of the world could a being have with no sense other than hearing, and Scruton proposes a thought experiment that he calls "The music room" (1997, 3). McGinn sketches a similar line of reasoning in his $(1999,44)$.

4 Conspicuous testimonies of the relevance of Strawson's thought experiment to contemporary philosophy of sound can be found in Nudds and O'Callaghan (eds.), 2009, especially the essays by Hamilton, Scruton, and Casati and Dokic. See also Casati and Dokic (2011).
} 


\section{Purely auditory experience}

Strawson's thought experiment rests upon the assumption that, even though most sounds are experienced as involving a certain distance or direction, there are cases (such as listening to music through headphones) in which the auditory experience seems to be purely temporal. Some philosophers, however, have questioned this assumption. Nudds (2001) does so by arguing that auditory experience is still essentially spatial since it is tied to other spatial senses such as vision and touch. Yet, what Strawson needs for his experiment is just the possibility that some subject of experience can experience some sound in this way, regardless of the multifarious ways in which humans beings do in fact experience sounds. For Strawson's hypothesis to hold it is sufficient to admit what Nudds himself seems to admit: "one can hear a particular sound without hearing it as having any spatial properties" $(2001,215)$.

O'Callaghan (2010) goes one step further by arguing that there is no way to conceive of a non-spatial experience of sounds. He considers the case of "minimal auditory experiences" such as the awareness of a uniform sinusoidal tone at a given loudness with none of the cues required for binaural spatialization. This, he holds, "might count as minimally auditory without furnishing the materials for concepts of spatial relationships" $(2010,136)$. He then observes: "It is unclear whether it is correct to describe such a minimal auditory experience as non-spatial, or whether it ought instead to be described as the experience of sound 'all around"' $(2010,136)$. Yet, the very fact that "It is unclear whether it is correct to describe such a minimal auditory experience as nonspatial" seems to show that we can conceive of it as non-spatial, and that is sufficient in order to make Strawson's thought experiment possible.

\section{The housing function}

According to Strawson, the notion of objective reality involves the notion of self-standing particulars - individuals existing independently of any experience of them. Some of them are, and others - in suitable conditions - could be, objects of experience for a subject who in principle could reidentify them in distinct experiences occurring at different times. Such reidentification on the part of a subject rests upon the fact that the entity in question remains the same not in the sense of mere qualitative sameness, but in the much stronger sense of numerical identity. That is what Strawson basically means when he speaks of "individual entities" or "individuals."

The main question that Strawson addresses in Chapter II of Individuals is whether this notion of an objective reality can be satisfied by individual entities existing only in time. He considers 
sounds whose experience involves a temporal succession but not a spatial ordering. As purely temporal individuals, these sounds are characterized only by their pitch, loudness and timbre, and by their position in the temporal succession. The No-Space world is inhabited by these sounds and by at least one subject of experience who can hear them - a pure hearer whom, following Evans (1980, 276), we will hereafter call "Hero."

If the sounds of the No-Space world constitute an experienceable objective reality, Hero should have the possibility of "identifying a particular sound as the same again after an interval during which it is not heard" (Strawson 1959, 70). In order to examine whether such reidentification is possible, it is worth noting, first of all, that what Hero experiences at a given moment are not whole auditory individuals, but only parts thereof. While visual experience is basically an experience of objects that we perceive as persisting thorough time, auditory experience rather concerns processes that we perceive as extended in time. Therefore, in the NoSpace world, the reidentification of sounds, understood as individual entities, concerns processes, not objects. While visual reidentification amounts to recognizing that two objects seen at different times with an experiential gap between them are the same individual, auditory reidentification rather amounts to recognizing that two parts heard at times separated by an experiential gap belong to the same process-like individual, namely a particular sound. The phenomenology of our ordinary auditory experience suggests that we are capable of fulfilling such task, for example when we hear a noise, and then plug our ears, and then hear that noise again. The same basic capacity can thus be assigned to Hero. Still, there remains a more fundamental requirement for reidentification in the No-Space world. This requirement concerns not Hero's capacities but the very nature of the sounds that inhabit that world.5

In our spatiotemporal world, indeed, reidentification is possible because the structure of space allows us to distinguish between what is inside and what is outside with respect to the spatial domain defined by the reach of our senses at a certain moment:

The possibility of reidentification of particulars depends on the idea of a dimension in which unperceived particulars may be housed, which they may be thought of as occupying. But, for our ordinary world, the word 'housed' is barely a metaphor and the word 'occupying' is not a metaphor at all. For in our ordinary world that 'dimension' is, precisely, three-dimensional space (Strawson 1959, 78, our emphasis).

\footnotetext{
5 Criticisms of Strawson's thought experiment that insist on Hero's limited capacities for reidentification can be found in Locke (1961), Swanson (1967), and Rosenberg (1978). They mainly focus on Hero's alleged incapacity to identify and reidentify auditory individuals that are simultaneous or indiscernible. Still, the fact that there can be some (indiscernible) individuals that Hero cannot (simultaneously) identify seems to be only an epistemological limit of Hero, not an ontological flaw of the No-Space world.
} 
By providing locations in which things can also exist beyond the reach of experience, space allows things to exist unperceived, thereby yielding what we will call - by analogy with an offstage situation in theater - an 'off-experience existence.' If, as seems to be the case in the NoSpace world, the only available 'dimension' is time, then both Hero's experience and all sounds at a certain moment will occur in one and the same 'location,' namely the present time, and therefore there seems to be no room for an off-experience existence.

To sum up, objective reality involves the possibility of reidentification, which requires the possibility of an off-experience existence, which in turn requires that something can fulfill "the necessary non-temporal dimension for, so to speak, the housing of the objects which are held to exist continuously though unobserved" (Strawson 1959, 74, our emphasis). In our spatiotemporal world such a housing function is fulfilled by space. What could fulfill this function in a No-Space world?

Strawson addresses this problem by introducing the notion of a master-sound, i.e. a sound that is always audible by Hero and that has its own peculiar timbre, constant loudness, and varying pitch. In the No-Space world, the master-sound determines the reach of Hero's experience. At a certain point in time $t$, Hero can only experience the sounds that, at $t$, have a pitch in the proper relation with the master-sound's pitch at $t$, viz., the former is "at the same pitch level or nearly the same pitch-level" as the latter (Strawson 1959, 85). This is the natural law, so to speak, that governs experience in the No-Space world. Thus, Hero can hear a certain sound X because X's pitch is close enough to that of the master sound, and he can distinguish $\mathrm{X}$ from the master sound since X's timbre is different from that of the the master-sound (as a $\mathrm{C}$ played on a piano differs from the same $\mathrm{C}$ played on a violin). In order to illustrate the functioning of the master-sound, Strawson compares it to the functioning of a wireless set:

Variations in the pitch of the master-sound are correlated with variations in the other sounds that are heard, in a way very similar to that in which variations in the position of the tuning-knob of a wireless set are correlated with variations in the sounds that one hears on the wireless. (Strawson $1959,76)$

In this way the master-sound seems to be able to fulfill in the No-Space world the function fulfilled by space in the world of ordinary experience, that is, to allow the distinction between inexperience existence and off-experience existence which is the basic requirement for an objective reality. 


\section{Permanence}

Evans (1980) criticizes Strawson's thought experiment arguing that the master-sound is insufficient to fulfill the housing function that we need in order to have objective reality in the No-Space world. The master-sound just explains how sounds enter and exit the reach of experience. In order to show that the sounds in the No-Space world have objective reality, however, one needs to explain how such sounds can exist outside the reach of experience, independently from their entering or exiting that reach. The real metaphysical requirement for the objective reality of sounds in the No-Space world is not their relation to the master-sound, which allows their reidentification, but rather their permanence in time, their "continued existence" independently of their being experienced and therefore identified or reidentified. Such a permanence requires a distinction between subjective time (in which a certain series of experiences occurs) and objective time (in which a thing previously experienced in that series may keep existing even when unperceived). The key question of the thought experiment could thus be rephrased as follows: can we conceive of an objective time, distinct from subjective time, without postulating an objective space? How can objective time be objective without a spatial dimension in which to house unperceived entities? Where do sounds go when they exit the reach of experience?

From Evans's perspective, the answer is that sounds never exit the reach of experience, so they never end up anywhere else. That is precisely because in the No-Space world there is no space but only time. The very notion of reach of experience, understood as a sort of spatial frame, has to be given up. If at certain times some auditory individuals exist unperceived, the reason is not to be found in their positional relation to Hero, but in Hero himself. Hero does not lack the proper location from which to perceive such individual entities. Instead, he lacks the proper subjective state that would be required to perceive them, for example, because he is asleep or unconscious.

Strawson rejects a view of this sort because he thinks that it is impossible to distinguish failures of experience from changes (such as fading away) of experienced things. There seems nonetheless to be a way to defend Evans' thesis that the continued existence of temporarily unperceived individuals can be explained in terms of failures of experience if we can point to phenomenological differences between failure of experience and processes such as fading away on the side of things given in experience. There seems to be such a distinction in our ordinary experience: consider the difference between seeing something blurrily and seeing something evaporating. Likewise, the experience of a failure in hearing a sound (for example, because the 
tuning-knob of a wireless set is turned so as to make that sound inaudible), seems to be phenomenologically different from the experience of hearing that very sound ceasing to exist, as a melody that fades smoothly into silence.

\section{Space-occupying stuff}

As we said, from Evans' perspective, off-experience existence in the No-Space world turns out to be a kind of existence that takes place within the reach of a possible experience. Such experience is prevented, at any given moment, by failures on the part of the subject. In order to account for such failures, Evans conceives of sounds in the No-Space world as having "dispositions to affect sensitive beings with certain experiences" $(1980,268)$. Thus failures in Hero's experience occur when Hero lacks the condition that is necessary to actualize the dispositions of such auditory entities to affect him.

The notion of disposition leads Evans to focus on the distinction between primary and secondary properties. In his view, primary properties are those that an entity always actually has, while secondary properties are dispositions to affect subjects that an entity always potentially has, but that are only actualized under certain conditions.

Primary properties are indispensable for an entity to keep existing even when unperceived, since secondary properties, as dispositions, are only actual under certain conditions, while permanence requires that an entity actually exists even when its dispositions are not actualized. Only in this way can that entity work as causal ground for its secondary properties, which, as dispositions, are able to make that very entity experienceable. However, according to Evans, in order to characterize primary properties we need notions such as position, shape, size, and, more generally, an underlying "theory of bodies." The latter in turn requires some "concept parallel to that of matter or material substance" (Evans 1980, 268). To sum up, sounds, as perceivable entities, must have dispositions to be perceived. Such dispositions are secondary properties, which require a causal ground of primary properties, which in turn require a body, made of what Evans calls "space-occupying stuff” $(1980,296)$. Hence the notion of space is back in play.

The notion of space-occupying stuff seems to be a requirement not only for the experienceable auditory entities in the No-Space world but also for Hero, the subject of experience. As sounds must have the possibility to exist unperceived, so Hero must have the possibility to exist unperceiving. Furthermore, in order to have experiences, Hero must have the disposition to be affected by sounds. But dispositions are to be grounded in some spaceoccupying stuff. Therefore, Hero must be made of some space-occupying stuff - in other words, 
he reveals himself to be an embodied individual, an individual that essentially has a body. Finally, if Hero has the disposition to remember past experiences, there must be some place in which past experiences are housed as memories when they are not actually experienced, and so once again something spatial. This issue of the spatiality of memories becomes particularly important when it comes to the social world, as we shall see in the final section.

\section{Stuffless bodies}

Evans's discussion of Strawson's thought experiment yields the conclusion that a sound in the No-Space world, in order to be able to exist off-experience, requires a body, understood as spaceoccupying stuff. In his reply to Evans on this point, Strawson (1980) contends that, as we can think of a merely sensory world, so we can think of individual entities constituted of nothing but sensory features. He thus suggests that an objective reality does not necessarily consist of bodies understood as portions of space-occupying stuff. It requires only some permanent ground that can play the role that material bodies play in our ordinary world. In order to make an objective reality experienceable, therefore, we just need entities that may elicit experiences and have a way to exist unperceived, and at least a subject capable of having such experiences. Bodies made of space-occupying stuff can surely ground the existence of things perceived at times and unperceived at other times, but there can be different means to the same end.

From this perspective, Strawson criticizes Evans for overlooking the possibility that we might conceive colors and sounds as individual entities in their own right, rather than as dispositions that have the primary properties of a material body as their causal ground. Strawson makes this point by focusing on the case of a purely visual world, whose subject of experience, which he calls "Seer," perceives patches of color that are purely visual objects. Those patches can keep existing when they exit the reach of Seer's experience by virtue of their intrinsic spatiality. Seer's world has an objective reality even if it has no space-occupying stuff.

Strawson's point is that being sensory is not logically coextensive with being minddependent. The two are only empirically co-extensive - in our world, made of embodied minds and material things. Yet, in a purely sensory world, sensory individuals could be - indeed, would have to be - mind-independent. For example, in a purely visual world an individual does not only appear red, but really is red. It has color among its durable actual properties. It has a stuffless body constituted by color itself. While in our world the sensory features of appearances are caused by the real features of things, in a purely sensory world things are made of nothing but the sensory features that appearances attribute to them. Thus, appearances are no longer a veil 10 
between the mind and the world, but rather a set of features that the mind shares with the world. In this sense Strawson $(1980,280)$ claims that a purely sensory world is such that it validates a "direct realist view of perception" according to which sensory features are also real features, instead of a "representative theory" according to which sensory features are caused by real features.6 Likewise, in a purely sensory world, the subject of experience can be conceived of as a sort of Cartesian self, that is, a disembodied individual constituted by nothing but its own appearance that shows up in introspection.

Seer's purely visual world, including spatial features among its purely visual patterns, makes stuffless bodies and therefore objective reality possible, regardless of the lack of space-occupying stuff. That is because Seer's world has a stuffless - purely sensory - space. Yet Hero's purely auditory No-Space world lacks not only space-occupying stuff, but also space itself. Hero's world is therefore both a No-Space and a No-Stuff world - a world in which there seems to be nothing capable of compensating for the lack of stuff. So, "If Seer survives, must Hero perish?" (Strawson 1980, 281).

In order to try to save Hero and his No-Space world, let us go back to Individuals. At the end of chapter II Strawson makes an amendment to his thought experiment. He introduces a new element that can help us challenge Evans' claim that objective reality requires a body to be understood as a space-occupying stuff. What Strawson suggests here is that, while we surely need bodies, we do not have to think of them as made of space-occupying stuff. Neither do we have to conceive of them as spatial:

The problem of equipping [the inhabitant of the No-Space world] with a persistent audible body may perhaps be solved by means of the master-sound itself. It is audible to him all the time, and we may suppose that for each inhabitant of the auditory world, there is a master-sound of a different timbre, though no one hears another's except when it is at the same pitch level or nearly the same pitch-level as his own. Two hearers are then in the same auditory place. (Strawson 1959, 84-85)

We can thus move from a unique Master-Sound to a plurality of master-sounds, and turn these master-sounds into the persistent audible bodies of the No-Space world's inhabitants. Some of them are also subjects of experience - let us call them 'heroes' - while others are only experienceable auditory entities. As in our world there are subjects and objects made of material bodies, so in this amended No-Space world there are subjects and processes made of master-

\footnotetext{
$6 \quad$ In a purely sensory world things can exist also off-experience precisely because their sensory features are not only subjective appearances but also real features. Chalmers (2006) labels such a purely sensory world as "Edenic" and argues that our ordinary experience represents the physical world by presenting an Edenic world.
} 
sounds. In this way, we obtain an auditory analogue of space and spatial bodies. Each body is a master-sound, and a hero having a body $\mathrm{X}$ can perceive another body $\mathrm{Y}$ when $\mathrm{X}$ is "at the same pitch level or nearly the same pitch-level" as Y, that is, in Strawson's terms, when they are "in the same auditory place." This means that the pitch level of master-sounds in the No-Space world functions as an analogue of the spatial position that material bodies occupy in our spatial world. There can be, of course, a theoretical difficulty in explaining how heroes as subjects of experience can emerge from master-sounds, but in fact, in our spatial world, we have the same kind of theoretical difficulty in explaining how we manage to emerge as subjects of experience from the space-occupying stuff constituting our brains.

In sum, what an objective reality requires is not space as such, but just an ontological structure that supports off-experience existence. We will now show that not only sounds but also social entities can be part of an objective reality of this kind, thereby allowing a realism that broadens the scope of the real in a genuinely "new" way.

\section{No-Space Artifacts}

The possibility of our thinking of non-spatial experiences, either auditory or of other kinds, rests upon the fact that our experience in general is not intrinsically spatial. What holds for sounds in Strawson's thought experiment seems to also hold for our mental states. We perceive things in space, but we do not have to experience our perception and feelings as being thereby also spatial, though their contents often are spatial. Our mental states do not exhibit spatial relations between each other. We experience them rather as being just temporal, that is, as being part of an ordered temporal series.

For example, a state of seeing can precede, or follow, or be simultaneous with, a state of hearing, but these states do not exhibit any spatial relation between them. Only their contents, that is, what is seen and what is heard, can possibly have spatial relations, not the states themselves. Occurring mental states are structured like notes in a musical work rather than like points in space. As several notes may simultaneously occur in a musical work, for example in polyphonic music, so different mental states, for example an experience of a visual image imagination and an emotion, may simultaneously occur in a subject of experience, but neither the simultaneously occurring notes nor the simultaneously occurring mental states are spatially related. The image of a "stream of consciousness" seems to grasp precisely such a basically temporal structure ordering mental states. 
That being the case, we do not experience our mind, understood as the subject of all those mental states, as a spatial thing. As McGinn puts it:

[...] there is this strange incongruity in the relation between mind and world: the world outside us is essentially spatial and we represent it that way in our every experience, yet our experience is itself essentially nonspatial. [...] The mind thus depends upon the spatial world, in the form of the brain, and it represents a spatial world, yet it itself steadfastly refuses to set foot in space. (McGinn 1999, 111)

The No-Space thought experiment shows that both sounds and selves, while not being intrinsically spatial, need at least some analogue of space and spatial bodies in order to account for the possibility of an entity that can endure in time through off-experience periods.

In this last part of our paper, we will try to extend this argument from sounds and selves to those individual entities that are created within a given culture through an acts of communication - particular social entities that can have a continued existence within a culture even if in some periods nobody thinks of them. Since acts of communication can be made by selves through sounds, it seems plausible that in a world in which there are only sounds and selves there could be acts of communication and entities created by them. Consider for example particular entities such as words, poems, music compositions, friendships, obligations, roles, and rules. Could such individuals exist in the No-Space world?

For this to be possible, the first condition to be fulfilled is that heroes, i.e. the subjects having master-sounds as their auditory bodies, are capable of initiating sounds and using them to communicate. Strawson suggests a way in which heroes can be endowed with the capacity for communication along these lines:

We may, for example, suppose our inhabitant of the auditory world to be able not only to initiate movement along the pitch-range of the master-sound, but also to initiate sounds of a different character from those not initiated by him - endow him, so to speak, with a voice. [...] This seems to open the door to something like communication. (Strawson 1959, 84-85)

By communicating in this way, heroes might create for example a game of chess, which - like blind chess in our own world - would require only acts of communication by the players against a background of shared understanding (Smith 2008, 35-38). In a similar way, poems and musical compositions might be created in the No-Space world - by analogy with the poems and songs generated in pre-literate cultures and preserved through oral tradition. And heroes in the NoSpace world can also create obligations - the informal normative entities which arise just through speech acts. 
Still, in order to create things such as contracts, there would need to be some sort of record that would allow the resolution of the sorts of disputes which arise, for example, when memories of the original contractees have had time to fade. In our world, we can only emit sounds that last as long as we are speaking. Therefore, in order to record an act of communication we need something like written documents to supplement private memories. However, we can imagine that in the No-Space world heroes can emit two kinds of sounds. The first is just like the kind of ephemeral sounds that we emit, but the second is slightly different. If a hero says "I promise", the produced sound is "I shall do such and such, I shall do such and such, I shall do such and such ..." as if there were an enduring echo. Call it a sound loop. We can imagine such echoes enduring for sufficiently long that they are able to function in the No-Space roughly as documents function in our own world. They are publicly accessible and they can provide an act of communication that occurred in a particular circumstance with a certain permanence in time. Sound loops can function as basic documents in the No-Space world, thereby showing that at least part of what is essential to a document is not its being spatial, but rather its being iterable. Such No-Space documents are basic in the sense that they seem to lack many features of documents (viz. you cannot store them, check them for accuracy, use them as security, etc.). Nonetheless, they seem to fulfill a basic function of documents, namely turning a singular act into something repeatable.

If all of this is right, the No-Space experiment provides us with a criterion to characterize a family of artifacts having an ontologically distinctive feature. We will label them 'No-Space artifacts.' Unlike concrete artifacts such as tables or chairs or poker chips or currency notes, Nospace artifacts - like nursery rhymes or games of chess or obligations - are able to exist also in a No-Space world. The only bounds to the importation of No-space artifacts from our world into the No-Space world seems to be set by the possible content that such artifacts articulate. For example, in the No-Space world there can be a poem concerning a certain sound but, quite obviously, there cannot be a poem concerning a certain mountain. Just like mental states, NoSpace artifacts, in our world, often refer to spatial entities; however, as this thought experiment reveals, their ontological structure is not essentially spatial.

Where sounds are perceptible No-Space artifacts can be conceived as thinkable; they typically also rest on auditory entities (acts of communication) for their beginning to exist. Still, it is worth noting that No-Space artifacts can also be experienced through peculiar mental states as, for example, pangs of conscience or feelings of guilt, which are neither perceptions nor thoughts strictly understood.

Just like No-Space sounds, No-Space artifacts can only belong to objective reality if they can 
have a continued existence even through off-experience periods. As we said, an existence of this kind requires space, or an analogue of space, since we need some place to house the entities in question when no one is thinking of them. In our ordinary world, this housing function is fulfilled in the first instance by memories, or rather by the sort of network of synaptic connections that makes memories possible. Recordings such as writings and documents can significantly strengthen such a network, and for some kinds of No-space artifacts they are actually indispensable (cf. Smith 2008, 43-44; and Ferraris 2005 and 2009). On the other hand, in the NoSpace world, the same function can be fulfilled, at least to some degree, by sounds along the lines described.

To sum up, phenomenal entities like sounds, entities based on shared intentions like games of chess, semantic entities like words, and normative entities like obligations can have an objective reality even in a No-Space world. From this perspective, phenomenology, intentionality, semantics, and normativity are not essentially bound to physical space. Interestingly, these are precisely the features of our "manifest image of man in the world" that the "scientific image" finds it hardest to deal with.7

\section{References}

Casati, R., and Dokic, J. 2009. "Some Varieties of Spatial Hearing,” in Nudds, M., and O'Callaghan, C. (eds.), Sounds land Perception: New Philosophical Essays, Oxford: Oxford University Press. . 2014. "Sounds," The Stanford Encyclopedia of Philosophy (Fall 2014 Edition), Zalta, E. N. (ed.) URL =

<http://plato.stanford.edu/archives/fall2014/entries/sounds/>.

Chalmers, D. J. 2006. "Perception and the Fall From Eden," in T. S. Gendler, J. Hawthorne (eds.), Perceptual Experience, Oxford: Oxford University Press. 49-125.

Evans, G. 1980. "Things Without the Mind," in van Straaten, Z. (ed.), Philosophical Subjects: Essays Presented to P.F. Strawson, Oxford: Clarendon Press, 76-116. Second edition in Evans, G. 1985. "Things Without the Mind," in his Collected Papers, Oxford: Oxford University Press, 249-290.

Ferraris, M. 2014. Where Are You? An Ontology of the Cell Phone, New York: Fordham University Press (original Italian edition: 2005). 2012. Documentality: Why It Is Necessary to Leave Traces, New York: Fordham University Press (original

$7 \quad$ See Sellars 1963, especially section 7: "Putting man into the scientific image." 
Italian edition: 2009).

Hamilton, A. 2009. “The Sound of Music,” in Nudds, M., and O'Callaghan, C. (eds.) 2009. Sounds and Perception: New Philosophical Essays. Oxford: Oxford University Press.

Locke, D. 1961. “Strawson’s Auditory Universe,” Philosophical Review, 70, 518-532.

McGinn, C. 1999. The Mysterious Flame: Conscious Minds in a Material World, New York: Basic Books.

Nicod, J. 1924. La Géometrie dans le Monde Sensible, Paris: Félix Alcan.

Nudds, M. 2001. "Experiencing the Production of Sounds," European Journal of Philosophy, 9:2, 210-229.

Nudds, M., and O’Callaghan, C. (eds.) 2009. Sounds and Perception: New Philosophical Essays. Oxford: Oxford University Press.

O’Callaghan, C. 2010, "Perceiving the Locations of Sounds," Review of Philosophy and Psychology, 1 (1), 123-140.

Rohrbaugh, G. 2003, “Artworks as Historical Individuals,” European Journal of Philosophy, 11, 2, 177-205.

Rosenberg, J. F. 1978. “On Strawson: Sounds, Skepticism, and Necessity,” Philosophia 8, 2, 405-419.

Scruton, R. 1997. The Aesthetics of Music, Oxford: Clarendon Press. 2009. "Sounds as Secondary Objects and Pure Events," in Nudds, M., and O'Callaghan, C. (eds.) 2009. Sounds and Perception: New Philosophical Essays. Oxford: Oxford University Press.

Sellars, W. 1963. "Philosophy and the Scientific Image of Man,” in Science, Perception and Reality 2, 35-78.

Smith, B. 2003. "John Searle: From Speech Acts to Social Reality,” in Smith, B. (ed.), John Searle, Cambridge: Cambridge University Press, 1-33. . 2008. "Searle and De Soto: The New Ontology of the Social World," in Smith, B., Mark D., Ehrlich I. (eds.), The Mystery of Capital and the Construction of Social Reality, Chicago: Open Court, 35-51.

Strawson, P.F. 1959, Individuals: Essay in Descriptive Metaphysics, London, Methuen. 1966, The Bounds of Sense: An Essay on Kant's Critique of Pure Reason, London, Methuen. . 1980, "Reply to Evans," in Van Straaten, Z. (ed.), Philosophical Subjects: Essays Presented to P. F. Strawson, Oxford: Clarendon Press, 273-282.

Swanson, J.W. 1967, “On a Problem of Nicod and Strawson,” Philosophy and Phenomenological Research, Vol. 28, No. 2, 222-229.

Thomasson, A. 1999, Fiction and Metaphysics, Cambridge: Cambridge University Press. 